\title{
REFERENCES
}

Bruce, H. M. \& Emmens, C. W. (1948). f. Hyg., Camb., 46, 315.

Greig, W. A. (1952). Brit. F. Nutrit. 6, 280.

Hignett, S. L. (1950). Vet. Rec. 62, 652.

Howie, J. W. \& Porter, G. (1950). Brit. F. Nutrit. 4, 175.

Richards, M. B. (1945). Brit. med. F. i, 433.

Richards, M. B. (1949a). Brit. F. Nutrit. 3, 109.

Richards, M. B. (1949b). Brit. Э. Nutrit. 3, 132.

Schmidt, M. B. (1928). Der Einfluss Eisenarmer und Eisenreicher Nahrung auf Blut und Körper. Jena: Gustav Fischer.

Shaw, I. G. (1950). Vet. Rec. 62, I87.

Simpson, B. W. (1947). Biochem. F. 4I, xlv.

\section{The Effects of Additions of Calcium Carbonate to the Diet of Breeding Mice}

\section{Haematology and Histopathology}

\author{
BY W. A. GREIG \\ Rowett Research Institute, Bucksburn, Aberdeenshire
}

(Received 9 August 195I)

Richards \& Greig (1952) reported pale livers and enlarged flabby hearts in weanling mice whose mothers' diets contained I-2 \% of added calcium carbonate. It seemed likely that the calcium carbonate had induced an unexpected anaemia in the young.

The work reported in the present paper was undertaken to investigate this possibility and to examine the pathology of the condition. The presence of anaemia was confirmed by haemoglobin estimations, and fuller examination of the blood indicated that it was probably of the iron-deficiency type. A further experiment showed that the anaemia could be prevented by feeding an iron supplement, but not by balancing the additional dietary calcium with sufficient phosphorus to restore the original $\mathrm{Ca}: \mathrm{P}$ ratio of the diet.

\section{METHODS}

The two reproduction experiments reported by Richards \& Greig (1952) provided the material for this work. The designs of both experiments have already been described in detail by these authors, and need only brief mention here.

Experiment I (Richards \& Greig, 1952).

Design. Sixteen litters of four female mice, stratified by weight, were allocated to four Latin squares with litter-mates distributed orthogonally. The other component variables of the squares were the calcium carbonate level of the diet (in vertical columns), and the levels of wheat and of casein in the diet factor (in horizontal rows). 
Each diet was a modification of the B diet of Sherman (Sherman \& Campbell, r924). Continuous monogamous mating was allowed for 80 days.

Haematological. All the weanlings in each available litter were examined at 21 days of age. The axillary vessels were resected under ether anaesthesia, and a sample of blood was withdrawn in a Haldane haemoglobin pipette. For a fuller blood examination, approximately $0.5 \mathrm{ml}$. was withdrawn and heparinized. A drop of fresh blood was used to prepare a blood film, and the animal was forthwith destroyed with ether. All subsequent examinations were performed on the heparinized samples. The mothers were dealt with in the same way, as they became available at the end of the breeding experiment.

Haemoglobin $(\mathrm{Hb}$ ) was estimated by Haldane's (Igor) carboxyhaemoglobin method. Erythrocyte counts (R.B.C.) and leucocyte counts (w.B.C.) were performed in the usual way, using Thoma pipettes and Neubauer haemocytometers, with Hayem's fluid and $\mathrm{I} \%(\mathrm{v} / \mathrm{v})$ acetic acid as diluents. Packed erythrocyte volumes (P.c.v.) were determined by means of capillary microhaematocrit tubes, spun for $I \mathrm{~h}$ at 3000 r.p.m. $($ R.C.F. $=c . \times 500 \mathrm{~g}$ ). Blood films were stained with Leishman's stain. The same items of apparatus were used throughout the observations, which were made by the same observers. The mean corpuscular haemoglobin (M.C.H.), mean corpuscular haemoglobin concentration (M.C.H.C.) and mean cell volume (M.C.v.) were then calculated from the appropriate observed data.

Histological. The hearts, livers, kidneys, spleens and thymus glands of both litters and mothers were fixed in $4 \%(\mathrm{w} / \mathrm{v})$ formol-saline (ro parts commercial formalin in 90 parts normal saline), or in formol-corrosive (Io parts commercial formalin in 90 parts saturated aqueous solution of mercuric chloride) (Lendrum, 1943). Paraffin sections were prepared in the usual manner, and stained by Mayer's (1903-4) haemalum and eosin. Frozen sections, stained with Scharlach $\mathrm{R}$ and haemalum, were prepared from the median lobe of the liver of each mother and of a representative of each litter. Smears were made from the femoral bone marrow of a number of weanlings and mothers in various diet-groups and stained with Leishman's stain. In addition, sections of bone marrow were prepared by the method advocated for sternal puncture material by Cappell, Hutchison and Smith (1947); these were stained with haemalum and eosin.

\section{Experiment 2 (Richards \& Greig, 1952)}

Design. Eight replicates of a $2^{3}$ factorial design were employed, the dietary variables being low or high levels of $\mathrm{CaCO}_{3}(0.5$ or $2.0 \mathrm{~g}$, respectively, added to $105 \mathrm{~g}$ basal diet), and the presence or absence of supplementary iron (ro p.p.m. as ferric citrate) or phosphorus $\left(0.57 \%\right.$ as $\left.\mathrm{NaH}_{2} \mathrm{PO}_{4} \cdot 2 \mathrm{H}_{2} \mathrm{O}\right)$ or both. The sixty-four female mice, in litters of four, were distributed so that two litters were allotted to each block of eight dietary treatments, with the interactions $\mathrm{CaCO}_{3} \times \mathrm{Fe}, \mathrm{CaCO}_{3} \times \mathrm{P}, \mathrm{Fe} \times \mathrm{P}$ and $\mathrm{CaCO}_{3} \times \mathrm{Fe} \times \mathrm{P}$ partially confounded between litters. Each mother was allowed to become pregnant for the second time before the male was removed from the cage.

Haematological. Each litter was represented, where possible, by two males and two females; these were the two animals nearest to the median weight of the weanlings 
of each sex in the litter. In general the same procedure was followed as in Exp. I, but the blood picture of all first litters and mothers was examined. Heller \& Paul's (1934) oxalate anti-coagulant mixture was used in place of heparin; leucocyte counts were omitted, but reticulocytes were examined in blood films stained supravitally with brilliant cresyl blue and counterstained with Leishman's stain. Only Hb estimations were done on the whole blood of second litters, but pooled samples of serum from each second litter were used to estimate serum inorganic phosphorus by King's (1946) method.

Histological. Frozen sections of the liver of each mother and of a representative of each first litter were examined.

RESULTS

Experiment I

Haematology

Litters. Since the haematological observations were begun only towards the end of the experiment, the data were incomplete. No first litters and very few second litters were available, so that most of the observations were on third and fourth litters. Diet-group means were computed by taking the mean for all the young in each litter,

Table I. Exp. I (litters). Mean blood haemoglobin of weanling mice from mothers with four levels of dietary calcium carbonate

\begin{tabular}{|c|c|c|c|c|c|}
\hline & Perce & $\mathrm{CaC}$ & $d$ to $\mathrm{m}$ & diet* & \\
\hline & 0 & 0.5 & $\mathrm{r}$ & 2 & S.E. \\
\hline $\mathrm{lb}(\mathrm{g} / \mathrm{100} \mathrm{ml} . \mathrm{blood})$ & 6.96 & $5 \cdot 77$ & $4 \cdot 88$ & 3.85 & \pm 0.755 \\
\hline
\end{tabular}

The values at the two lowest levels of $\mathrm{CaCO}_{3}$ are significantly greater than that at the highest level $(P<0.01$ and $<0.05$ respectively).

- In four of the sixteen diets used, additions of $\mathrm{CaCO}_{3}$ were per I05 parts instead of 100 parts basal diet (see Richards \& Greig, 1952).

and finding from these the mean for all the litters in each diet-group. The means were not weighted for either number in litter or number of litters, and data from second, third and fourth litters were considered together. Statistical analysis of the figures was possible only for $\mathrm{Hb}$; even here the small numbers precluded consideration of each diet-group separately, but the overall effects of modifications in the wheat-casein factor and of changes in the dietary $\mathrm{CaCO}_{3}$ level could be determined by combining, as marginal means, the values in each row (i.e. horizontally) and at each level of $\mathrm{CaCO}_{3}$ (i.e. vertically). The differences between the rows failed, in every instance, to reach significance, but the values for the first (no added $\left.\mathrm{CaCO}_{3}\right)$ and second $(0.5 \%$ added $\left.\mathrm{CaCO}_{3}\right)$ levels were significantly greater than the value for the last $\left(2 \% \mathrm{CaCO}_{3}\right)$ level $(P<0.01$ and $<0.05$, respectively), whereas values for the third level were intermediate (Table r).

Data on the other attributes are not presented here as they were too limited for a conclusive finding, but in general all measurements, including the calculated M.C.H. 
and M.C.H.C. but not, however, the M.C.V., tended to fall in the last two columns, thereby suggesting that the anaemia was hypochromic. This suggestion was borne out by the appearance of the erythrocytes in the stained films. Apart from the polychromatic cells normally found in mouse blood, the red cells of anaemic weanlings were mainly hypochromic, but orthochromatic cells similar to those described by Price-Jones (1932) were also present and stood out in contrast. Anisocytosis was invariable, and poikilocytosis frequent (Pl. I, I $a$ )

Mothers. Mean values and standard errors were calculated for each diet-group, row and $\mathrm{CaCO}_{3}$ level, as was done with the litter data. All but six of the sixty-four mothers were available for Hb, R.B.C. and w.B.c. determinations. For these attributes, and for the M.C.H., the arrangement of litter-mates in the design made it possible to isolate and eliminate the component of variability attributable to litter (i.e. genetic) differences. However, P.c.v. estimations could be made on only forty-two animals, and for this attribute and for the erythrocytic indices depending on it, the design had to be treated simply as randomized blocks.

The adjusted results are summarized in Table 2 . It will be seen that none of the differences between the rows reached significance; there was not even evidence of consistency between measurements. On the other hand, comparison between the

Table 2. Exp. I (mothers). Blood picture of mother mice on four basal diets, each with four levels of added calcium carbonate

(a) Method of calculating marginal means for $\mathrm{Hb}(\mathrm{g} / 100 \mathrm{ml}$.) from diet-group means

\begin{tabular}{|c|c|c|c|c|c|}
\hline \multicolumn{5}{|c|}{ Percentage of $\mathrm{CaCO}_{3}$ added to diet* } & \multirow{2}{*}{$\begin{array}{l}\text { Marginal } \\
\text { mean }\end{array}$} \\
\hline $\begin{array}{l}\text { Basal } \\
\operatorname{diet} \dagger\end{array}$ & $\mathbf{0}$ & 0.5 & $\mathbf{r}$ & 2 & \\
\hline Row I & 14 I9 & $14 \cdot 6 I$ & $13 \cdot 85$ & $12 \cdot 71$ & $13 \cdot 84$ \\
\hline Row 2 & $15 \cdot 33$ & 12.70 & 13.68 & $12 \cdot 96$ & 13.66 \\
\hline Row 3 & $15 \cdot 21$ & $14 \cdot 33$ & $15 \cdot 16$ & $12 \cdot 99$ & $14^{*} 43$ \\
\hline Row 4 & $15 \cdot 36$ & 14.49 & $13 \cdot 36$ & $11 \cdot 84$ & $13 \cdot 76$ \\
\hline \multirow[t]{2}{*}{ Marginal mean } & 15.02 & 14.03 & 14.02 & $12 \cdot 62$ & 13.93 \\
\hline & \multicolumn{2}{|c|}{ S.E. of differences between } & $\begin{array}{l}\text { Marginal } n \\
\text { Diet-group }\end{array}$ & $\begin{array}{l} \pm 0.662 \\
\pm I \cdot 146\end{array}$ & \\
\hline
\end{tabular}

(b) Marginal means for rows, and calcium carbonate levels determined from diet-group means as in (a) above

\begin{tabular}{|c|c|c|c|c|c|c|c|c|c|}
\hline \multirow[b]{2}{*}{ Attribute } & & Ro & $\mathbf{w}$ & 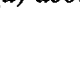 & & $\begin{array}{l}\text { centag } \\
\text { added }\end{array}$ & $\begin{array}{l}\text { of } \mathrm{Ca} \\
\text { to diet }\end{array}$ & & \\
\hline & $\mathbf{I}$ & 2 & 3 & 4 & o & 0.5 & I & 2 & S.E. \\
\hline $\mathrm{Hb}(\mathrm{g} / 100 \mathrm{ml})$. & 13.84 & 13.66 & 14.43 & $13 \cdot 76$ & 15.02 & $14 \cdot 03$ & $14 \cdot 02$ & $12 \cdot 62$ & \pm 0.662 \\
\hline R.B.C. $\left(10^{6} / \mathrm{cu} . \mathrm{mm}\right)$ & 10.6 & 10.4 & I I. 5 & 10.4 & $1 \mathrm{I} \cdot 2$ & 10.3 & I I.O & 10.4 & \pm 0.62 \\
\hline P.c.v. $(\%)$ & 45 & 41 & 45 & 42 & 48 & 40 & 44 & 42 & \pm 3.0 \\
\hline M.C.H. $(\mu \mu \mathrm{g})$ & I3.2 & $13 \cdot 3$ & $12 \cdot 7$ & $13 \cdot 3$ & I3.9 & I $3 \cdot 9$ & $12 \cdot 9$ & I $\mathrm{I} \cdot 8$ & \pm 0.92 \\
\hline M.C.H.C. (\%) & $30 \cdot 7$ & $34 \cdot I$ & $32 \cdot 3$ & $36 \cdot 8$ & $35^{\cdot 8}$ & $35 \cdot 8$ & $33 \cdot 7$ & $29^{\circ} I$ & $\pm 3 \cdot 69$ \\
\hline M.C.v. (cu. $\mu)$ & $42 \cdot 2$ & $40 \cdot 9$ & $40 \cdot 2$ & $40 \cdot 0$ & $43^{\cdot} I$ & $38 \cdot 8$ & 40.4 & $40 \cdot 6$ & \pm 3.37 \\
\hline W.B.C. $\left(\mathrm{IO}^{\mathrm{s}} / \mathrm{cu} . \mathrm{mm}\right)$ & $3 \cdot 9$ & $2 \cdot 4$ & $2 \cdot 8$ & $2 \cdot 4$ & $2 \cdot 4$ & $2 \cdot 9$ & $2 \cdot 4$ & $3 \cdot 7$ & $\pm 3 \cdot 73$ \\
\hline
\end{tabular}

Significant differences:

$\mathrm{Hb}$ is lower at $2 \% \mathrm{CaCO}_{3}$ level than at $0,0.5$ and $\mathrm{I} \%$ levels $(P<0.01,<0.05$ and $<0.05)$. M.C.H. is lower at $2 \% \mathrm{CaCO}_{3}$ level than at 0 and $0.5 \%$ levels $(P<0.05$ and $<0.05)$.

- In Row 4, additions of $\mathrm{CaCO}_{3}$ were per I05 parts instead of roo parts basal diet.

+ For details of the composition of these diets see Richards \& Greig (1952). 
columns (i.e. levels of $\mathrm{CaCO}_{3}$ ) showed that the mean $\mathrm{Hb}$ of animals on the diets containing the highest level of $\mathrm{CaCO}_{3}$ was significantly lower than that obtained at all other levels $(P<0.01,<0.05,<0.05)$. The mean M.C.H. at the $2 \% \mathrm{CaCO}_{3}$ level was also significantly lower than at the 0 and $0.5 \% \mathrm{CaCO}_{3}$ levels $(P<0.05,<0.05)$. There was also a suggestion that a similar relationship existed between the M.C.H.C. and the $\mathrm{CaCO}_{3}$ level of the diet. No significant effects were apparent on the other blood attributes.

There was thus considerable evidence that, in the mothers as well as the weanlings, the anaemia was hypochromic. Examination of stained blood films bore this out; the erythrocytes in the more anaemic bloods were pale and presented the same general characters as those of the weanlings.

For further confirmation of these findings, correlation coefficients between $\mathrm{Hb}$ and all other attributes were calculated from the data of each individual animal, ignoring treatment effects (Table 3 ). From these it was clear that $\mathrm{Hb}$ was strongly correlated

Table 3. Exp. I (mothers). Correlation coefficients between haemoglobin and other blood attributes, ignoring treatment effects

$\begin{array}{lcc}\text { Correlation } & r & P \\ \text { Hb and R.B.c. } & +0.460 & <0.001 \\ \text { Hb and P.c.v. } & +0.667 & <0.001 \\ \text { Hb and M.c.H. } & +0.531 & <0.001 \\ \text { Hb and M.c.H.C. } & +0.362 & <0.05 \\ \text { Hb and M.c.v. } & +0.254 & >0.10 \\ \text { Hb and w.B.C. } & +0.313 & <0.05\end{array}$

with M.C.H., the relationship being almost linear. This showed that in anaemic animals the haemoglobin carried by each erythrocyte diminished in proportion to the anaemia. The coefficients also confirmed that the blood of more anaemic animals (i.e. those with lower $\mathrm{Hb}$ values) had a lower M.C.H.C.; that is to say, the anaemia was hypochromic. No significant correlation, however, could be shown between $\mathrm{Hb}$ and M.c.v.; that is to say, the anaemia could not be shown to be other than normocytic. Table 3 also shows that there was a significant correlation between $\mathrm{Hb}$ and w.B.c., indicating that the anaemia was accompanied by a leucopenia. Except for the lack of demonstrable change in the M.c.v. (discussed later in this paper) these findings all suggested that the anaemia was of the type associated with iron deficiency.

\section{Experiment 2}

First litters. The summarized results for all haematological attributes measured are shown in Table $4(a)$. The mean value for each litter was first determined, and then the mean of all such litter means in each diet-group. These diet-group means are the figures quoted in the table.

The effects of the various treatments are in most cases obvious from inspection of the data, e.g. the effect of the higher $\mathrm{Ca}$ level on the unsupplemented diet is to reduce $\mathrm{Hb}$ from 5.00 to $2.66 \mathrm{~g} / \mathrm{ro0} \mathrm{ml}$., and to reduce R.B.C. from 5.4 to $3.4 \mathrm{million} / \mathrm{cu} . \mathrm{mm}$, and so forth. The significance of these differences $(2 \cdot 34$ and $2 \cdot 0$ respectively) can be determined in each case by using the standard error applicable to comparisons between 


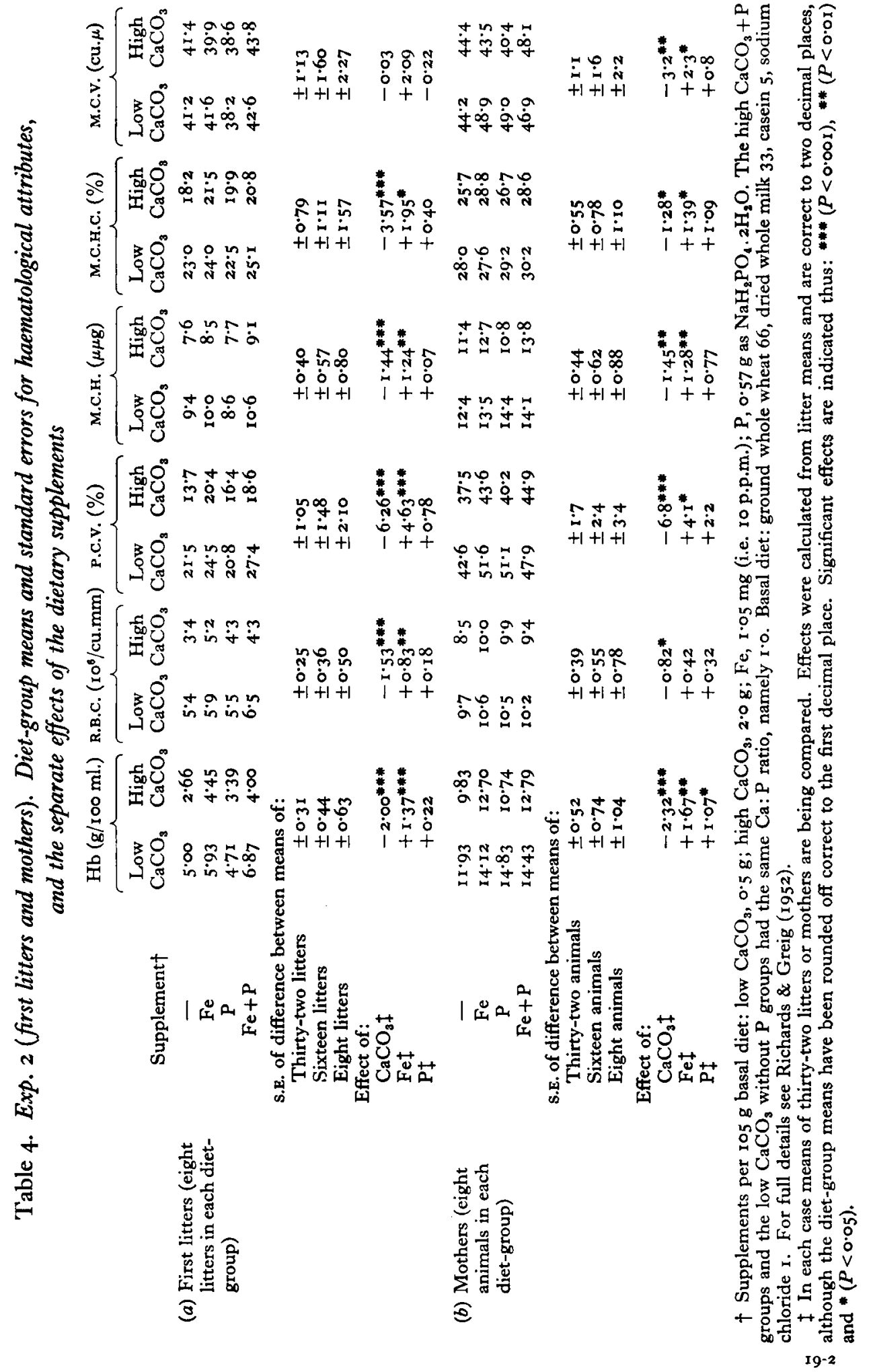


two diet-group means, i.e. the means of two sets of eight litters each. For $\mathrm{Hb}$ and R.B.C. these are \pm 0.63 and \pm 0.50 ; thus both differences are highly significant since they are three or four times as large as their respective standard errors. 'The significance of differences between any two treatments can be determined in this way.

Another estimate of the effect of a dietary treatment can be made by averaging its effects over all other treatments. This estimate is more accurate because it is based on a larger number of observations, and it is valid provided there are no important interactions. For instance, the overall effect of $\mathrm{Fe}$ on $\mathrm{Hb}$ is

$$
\frac{1}{4}(5 \cdot 93+4 \cdot 45+6 \cdot 87+4 \cdot 00)-\frac{1}{4}(5 \cdot 00+2 \cdot 66+4 \cdot 7 x+3 \cdot 39)=r \cdot 37 \text {. }
$$

This difference is more than four times its standard error (i.e. the S.E. of difference between means of sets of thirty-two litters, namely $\pm 0.3 \mathrm{I})$ and the difference is therefore highly significant $(P<0 \cdot 00 \mathrm{I})$. Comparisons between means of sixteen litters can be made on the same principle. When the overall effect of the higher $\mathrm{CaCO}_{3}$ level on $\mathrm{Hb}$ is determined in this way, it is seen to be more than six times its s.E. $(2.00>6 \times 0.3 \mathrm{I})$. The size, direction and significance of such effects are set out below each attribute in Table 4. The interactions $\mathrm{CaCO}_{3} \times \mathrm{Fe}, \mathrm{CaCO}_{3} \times \mathrm{P}, \mathrm{Fe} \times \mathrm{P}$ and $\mathrm{CaCO}_{3} \times \mathrm{Fe} \times \mathrm{P}$ were all tested, and in some instances appeared to reach significance at the $5 \%$ level; but as they were small in comparison with the main effects, and inconsistent in their directions, they could safely be ignored in considering main effects.

As can be seen from Table $4(a)$, the overall effect of $\mathrm{CaCO}_{3}$ in reducing $\mathrm{Hb}$, R.B.C., P.C.V., M.C.H. and M.C.H.C. was highly significant. Fe supplementation of the diet also produced significant effects on all these attributes, but in the opposite direction. In strong contrast was the fact that none of the dietary treatments could be shown to produce a significant effect on M.c.v. The effects of $\mathrm{P}$ never approached significance.

On this evidence, then, the higher level of $\mathrm{CaCO}_{3}$ in the mother's diet induced a hypochromic, normocytic anaemia, and litters from the non-Fe-supplemented dietgroups also exhibited hypochromic anaemia when compared with the $\mathrm{Fe}$-supplemented groups.

Examination of the supravitally stained smears (Pl. $\mathrm{I}, \mathrm{I} b$ ) showed that reticulocytes and late normoblasts were numerous in all specimens. Although systematic differential counts were not made on all smears, these cells appeared to be rather more numerous in the blood of weanlings from the high dietary- $\mathrm{CaCO}_{3}$ groups. In these animals, early normoblasts were also encountered, sometimes in considerable numbers. The mature erythrocytes were hypochromic, and anisocytosis and poikilocytosis were common.

Mothers. The same procedure was followed with the data from the mothers; the results are shown in Table $4(b)$. The differences were not always so large, but the directions of the effects were similar. Here, however, the effect of $\mathrm{P}$ on $\mathrm{Hb}$ was positive and just reached significance $(P<0.05)$, and the M.c.v. was significantly reduced by $\mathrm{CaCO}_{3}(P<0.0 \mathrm{I})$ and increased by $\mathrm{Fe}(P<0.05)$. The anaemia in the mothers induced by dietary $\mathrm{CaCO}_{3}$ was therefore hypochromic and microcytic, whereas lack of an $\mathrm{Fe}$ supplement in the diet also was responsible for a relative anaemia of this type. 
The stained blood smears of the mothers presented the same picture as those of the weanlings, except that young normoblasts were unusual.

Second litters. Results for second litters are shown in Table 5. The $\mathrm{CaCO}_{3}$ and $\mathrm{Fe}$ effects on $\mathrm{Hb}$ were again very strong $(P<0.00 \mathrm{I})$, and this time the effect of $\mathrm{P}$ was also significant $(P<0.05)$. The figures show that, compared with first litters (Table $4 a)$, second litters were improved in every diet-group $(P<0.01)$.

Table 5. Exp. 2 (second litters). Diet-group means and standard errors for blood haemoglobin and serum inorganic phosphorus, and the separate effects of the dietary supplements

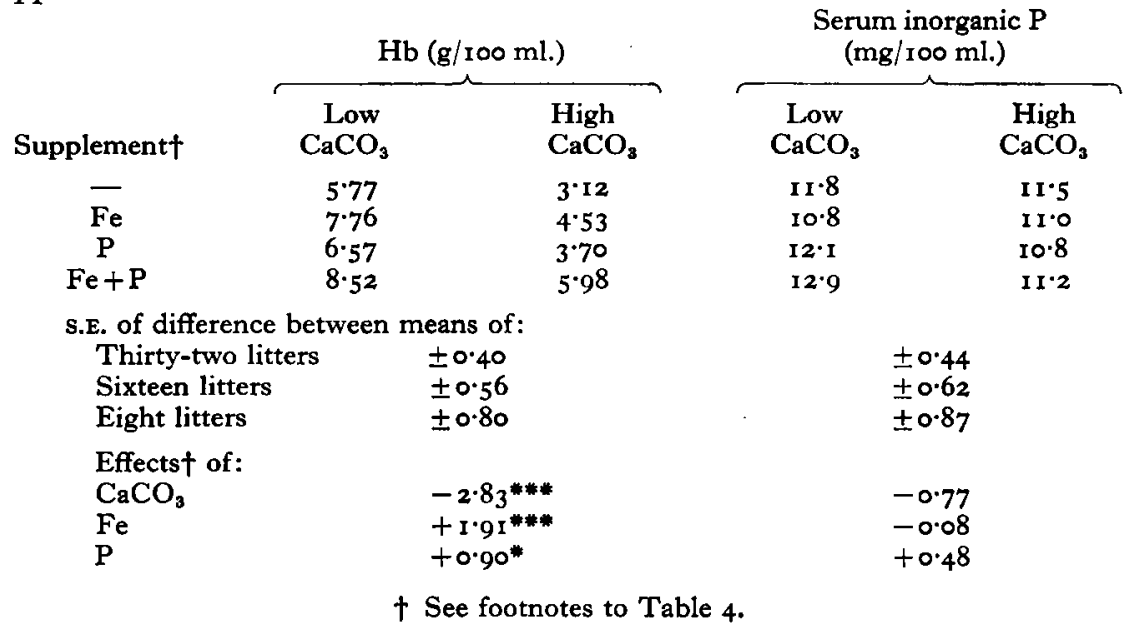

There were no significant effects on serum inorganic phosphorus. However, a striking hyperlipaemia was observed in serums from the most anaemic litters. This observation is receiving further study.

\section{Experiment I}

\section{Histopathology}

Hearts. The hearts both of mothers and of litters from the higher $\mathrm{CaCO}_{3}$-level groups were enlarged (Richards \& Greig, 1952). They exhibited marked hypertrophy of the individual muscle fibres and oedematous separation of the muscle bundles. In a number of the most anaemic weanlings from these groups, degenerative changes were apparent in the heart-muscle cells (Pl. I, 2). Fatty degeneration was never seen, but, in one particularly anaemic weanling, numerous calcified areas were observed scattered throughout the muscle tissue.

Thymus glands. Richards \& Greig (1952) found that the thymus glands of litters from the high $\mathrm{CaCO}_{3}$ diet-groups were smaller than those from other diet-groups, but histologically there were no signs of sclerosis or of degeneration in the thymocytes. However, the line of demarcation between cortex and medulla tended to be less distinct, which suggested that the organ had undergone premature involution. No differences were found in the thymus glands of mothers. 
Kidneys. The only abnormal features were early degenerative changes in the tubule cells of a few of the most anaemic weanlings. There was no evidence of fatty degeneration.

Spleens. There were no important differences in the structure of the spleens of either litters or mothers on different dietary treatments.

Livers. A certain amount of visible fat was present in sections of the livers of both adult and young mice on even the best diets in this experiment. In a few specimens the quantity of fat was small ( $\mathrm{Pl} .2, \mathrm{I})$, in many it was considerable (Pl. 2, 2), and in some enormous ( $\mathrm{Pl} .2,3)$.

In the weanlings, the impression was gained that the degree of fatty change was greatest when the level of $\mathrm{CaCO}_{3}$ in the mother's diet was highest. In order to corroborate this, the amount of visible fat in comparable sections from a mother and a weanling in each diet-group was assessed by an arbitrary,,++++++ system. With only one observation from each diet-group, the results were not suitable for statistical analysis. Nevertheless, they confirmed the impression, since in the weanlings the highest number of ' +' $s$ ' was recorded from the highest $\mathrm{CaCO}_{3}$ diet-group, and the lowest number from the two groups with the lowest $\mathrm{CaCO}_{3}$ levels. No association was apparent between the basal diet of each row and the amount of fat present in the liver.

The livers of the mothers were much more variable in their fat content, and no general correlation between liver fat and diet was evident. It was nevertheless true that those livers with the least fat came from mice on the lower $\mathrm{CaCO}_{3}$ diets, and those with the most from animals on the highest dietary $\mathrm{CaCO}_{3}$ level.

The distribution of the fatty changes within the lobule was also studied. When the amount present was small, the fat was generally distributed fairly evenly throughout each lobule (Pl. 2, I). On the other hand, greater amounts of fat were almost invariably situated in the centrilobular areas ( $\mathrm{Pl} .2,2)$. In the most severe cases, nearly every parenchymatous cell was affected, the appearance being almost that of adipose tissue, relieved only by small patches around the portal vessels (Pl. 2, 3).

The essential lesion in the hepatic cells was fatty degeneration. The earliest changes were manifested in the characteristic 'foam-cells' (Pl. 2, 4), in which the cytoplasm was partly broken down and contained droplets of fat. In more advanced stages, the cells were swollen and contained large vacuoles; and in the most severe cases only the cell wall remained, sometimes with the remains of the nucleus close against it, the cytoplasm having been completely replaced by immense fat globules.

Bone marrow. All the bone-marrow specimens examined were highly cellular, with hyperplasia of the erythroid cell series. The reaction was most marked in marrows from the high $\mathrm{CaCO}_{3}$ groups, which contained an abundance of immature red cells, particularly early and late normoblasts (Pl. I, 3 ).

\section{Experiment 2}

The procedure described under Exp. I (see above) was adopted to assess the amount of visible fat in each of the 128 liver sections. Objectivity in assessment was attained by labelling each slide with a code number which gave the observer no clue to the 
identity of the specimen, and by recording assessments by two independent observers. The summarized results are presented in Table 6 .

Table 6. Exp. 2 (first litters and mothers). Diet-group means and standard errors for quantity of visible liver fat, assessed $\mathrm{I}-4$ histologically, and the separate effects of the dietary supplements

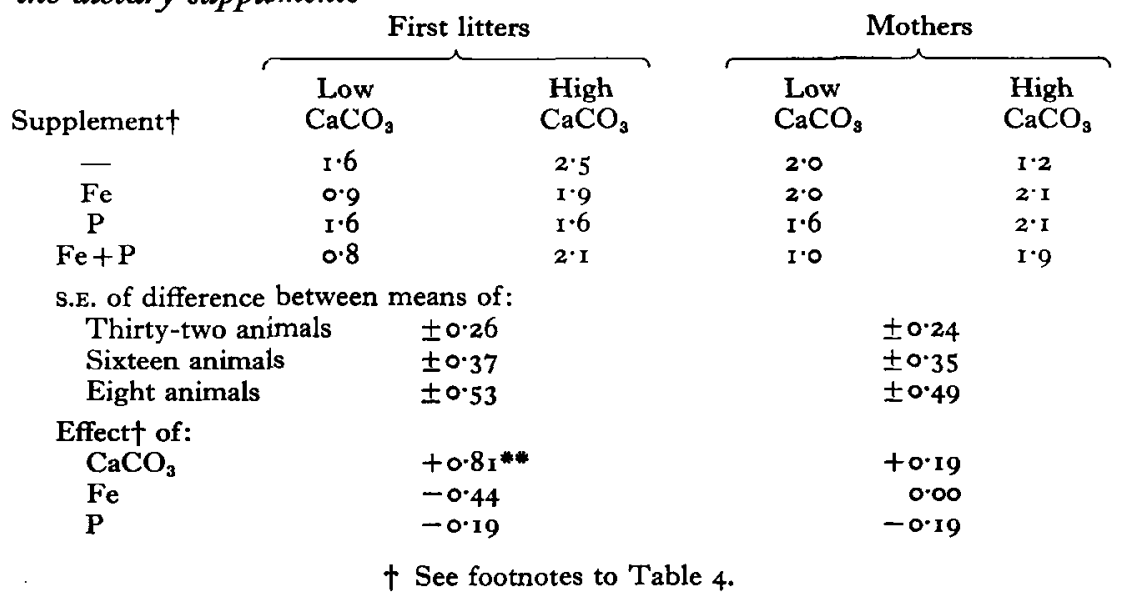

The effect of the $\mathrm{CaCO}_{3}$ additions to the mother's diet was to increase the amount of visible fat in the livers of weanlings $(P<0.01)$, and there was a suggestion that dietary Fe may have had the opposite effect. The effect of dietary $\mathrm{P}$ was not significant, nor were there any dietary effects on the livers of the mothers.

\section{DISCUSSION AND CONCLUSIONS}

In these experiments the main haematological findings were clear-cut: calcium carbonate, when added to the diet of breeding mice, induced a marked anaemia in both dams and litters. The immediate cause of the anaemia was undoubtedly an induced iron deficiency, and was evidenced by the hypochromic, anisocytic appearance of the erythrocytes in blood smears, the normoblastic reaction in the bone marrow and the quantitative haematological findings. The anaemia could be prevented by adding ferric citrate to the diet. The effects of the calcium carbonate could not, however, be neutralized merely by restoring the original $\mathrm{Ca}: \mathrm{P}$ ratio of the diet with a supplement of sodium dihydrogen phosphate.

The anaemia in both weanlings and mothers was characterized by much reduced $\mathrm{Hb}$, P.C.v. and M.C.H. values. The R.B.c. and M.c.H.C. were also decreased, markedly in the weanlings but less so in the dams. Only in the dams, however, did the supplements affect the M.C.V.; this was on the whole raised by $\mathrm{Fe}$ and lowered by $\mathrm{CaCO}_{3}$, although the effects were uneven. The relative magnitudes of all effects may be compared in Fig. I, which has been scaled so that for each attribute the standard errors are represented by equal positive and negative excursions from the base-line.

Discussing the haematology of iron-deficiency anaemia, Parsons (1938) states that, at least in rats, its course is characterized by three stages: there is at first a microcytosis 
with accompanying mild polycythaemia, then the erythrocytes become hypochromic, and finally erythropenia develops. The syndrome seen in the dams presented all these and many of the other accepted characteristics of iron-deficiency anaemia (see, for example, Whitby \& Britton, I950). The picture was generally similar in the weanlings, except that microcytosis could not be demonstrated, and that changes in the other haematological attributes were more pronounced than in the mothers.

In this connexion, it must be remembered that, as was found by Bacharach, Cuthbertson \& Thornton (1949), the effects of iron deficiency are more obvious in weanlings than in their dams. The basal diet in the present experiments contained
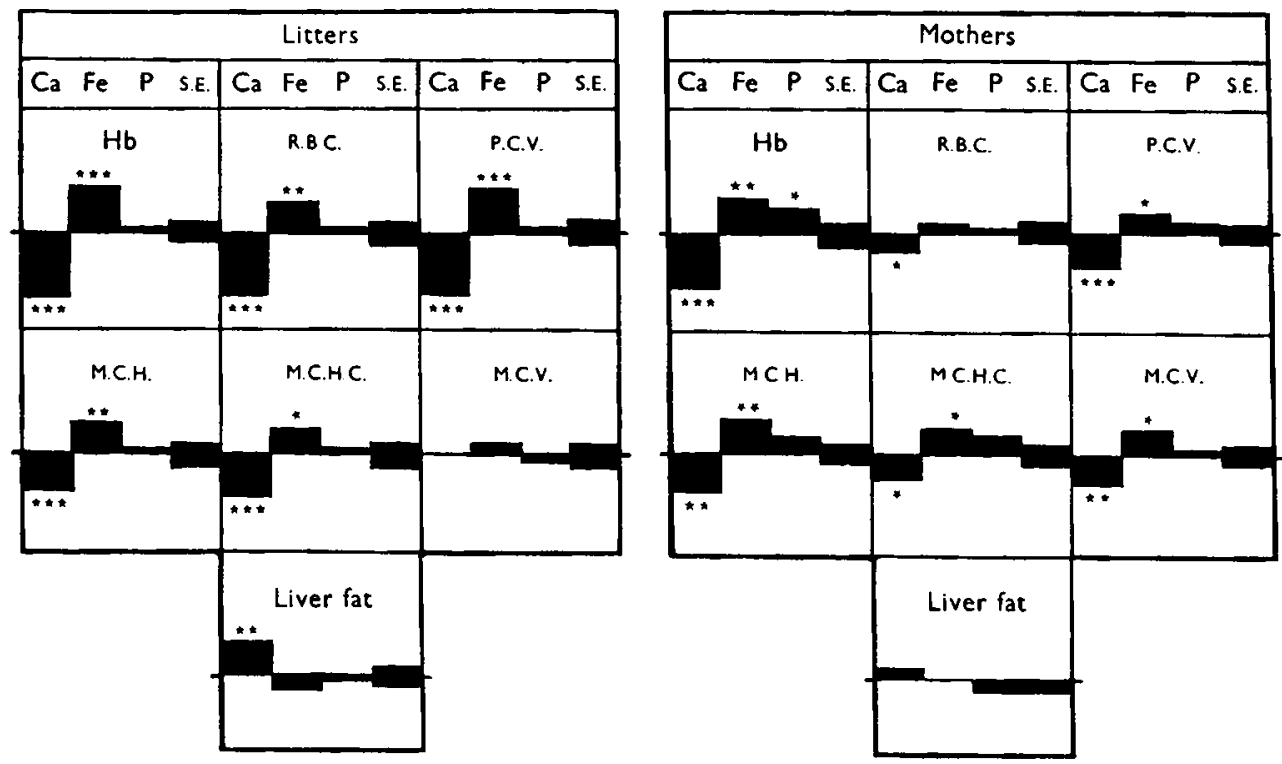

Fig. I. Exp. 2. Overall independent effects of dietary supplements, to show the relative influence of each on various blood attributes and liver fat. The base-lines represent the overall mean measurements; positive effects (i.e. increases) above the base-line, negative effects (i.e. decreases) below the base-line. The diagram has been scaled so that the standard error is represented in each instance by the same positive and negative excursions from the base-line. Significance of effects is indicated by * $(P<0.05)$, ** $(P<0.01)$ and *** $(P<0.001)$. Ca=effect of $1.5 \%$ supplement of calcium carbonate; $\mathrm{Fe}=$ effect of $\mathrm{I} O$ p.p.m. supplement of iron as ferric citrate; $\mathrm{P}=$ effect of $0.57 \%$ supplement of phosphorus as sodium dihydrogen phosphate; s.E. = standard error of the mean.

only 35 p.p.m. Fe (Richards \& Greig, 1952), so that animals from all diet-groups were to some extent iron-deficient; indeed, anaemia of the hypochromic microcytic type was already established in litters from even the low- $\mathrm{CaCO}_{3}$ groups, when compared with litters from several stock diets (unpublished observations). The relative differences between weanlings and mothers can therefore be explained on the grounds that the anaemia was much more severe in the weanlings, and consequently the first stage quoted above was not seen.

This explanation might also account for the failure to detect changes in the weanlings' M.c.v.; it would do so if microcytosis were either not progressive in irondeficiency anaemia or were masked in severe cases by anisocytosis which, as pointed 
out by Price-Jones (1932), is a feature of this condition. Certainly anisocytosis was well marked in these experiments (PI. I, I). It may have been that a species peculiarity served to aggravate the anisocytosis: polychromatic cells, which are relatively larger than mature erythrocytes, are always numerous in normal mouse blood. Consequently, they may enter the circulation in greater numbers in response to the stress of severe anaemia, although in other species whose blood normally contains only fully haemoglobinized cells, such young cells are seldom mobilized. Although $\mathrm{CaCO}_{3}$ did not reduce the M.C.v., it may not be unimportant that the effect of $\mathrm{Fe}$, which was to raise the $\mathrm{Hb}$ and so, presumably, to lessen the anisocytosis, approached statistical significance in raising also the M.c.v. It is thus possible that there were no overall effects on the M.c.v. of the weanlings because macrocytosis in the young cells balanced microcytic changes in the mature erythrocytes.

On the other hand, the estimation of M.c.v. is always subject to considerable technical error. It is calculated from a formula which reflects the errors of two observed measurements; in particular, the notoriously inaccurate R.B.C. is the denominator in the formula, so that random errors in its measurement are greatly magnified in the resultant M.c.v. This is true, of course, for all values of R.B.c.; but when the R.B.C. is small (as it was so often in the anaemic weanlings), not only will errors of the same magnitude affect the M.C.v. to a proportionately greater degree, but substantial errors in its own measurement are more likely. Averages of many observations were taken, and no doubt these errors cancelled themselves out to some extent, but it was clear from the full data for both mothers and litters that variability in the recorded R.B.C. was greatest in the most anaemic animals. This means that much of the variability, and hence error, in the M.c.v. of the most anaemic animals can be ascribed to random variation in the R.B.C. Probably both anisocytosis and random error were jointly responsible for the irregularity observed in the weanlings' cell volume.

The outstanding histological feature was the increased amount of fat in the livers of weanlings from the high $\mathrm{CaCO}_{3}$ groups. Whether this was a direct or an indirect effect of the supplement cannot be stated for certain, but it seems very likely that it was simply a reflexion of the severe anaemia, and was caused by local anoxia. This view is supported by the centrilobular distribution of the fat (areas farthest from the blood supply being most affected) and by degenerative changes in the other tissues, such as heart muscle and kidney tubules, which would probably be affected if the oxygen-carrying capacity of the blood were reduced. These changes did not, however, proceed to fatty degeneration. -

Schmidt (1928), working with mice on iron-deficient diets, reported similar histological findings and also observed the associated hyperlipaemia. At the same time, he frequently found fatty deposits, which he regarded as infiltrations rather than degenerations, in the myocardium, pulmonary alveolar cells, and glomeruli of the kidneys, and also centres of calcification in many of the enlarged hearts. Such lesions were not seen in the present experiments, apart from one instance of calcification in the myocardium; but in Schmidt's animals the anaemia was more chronic.

It would seem, then, that the whole syndrome can be explained on the hypothesis that dietary $\mathrm{CaCO}_{3}$ in some way interferes with the availability of $\mathrm{Fe}$, as was postulated 
by Richards $\&$ Greig (1952) for the effects of these diets on reproduction. The addition of phosphate, if it did not much help, certainly did not hinder $\mathrm{Fe}$ absorption. Previous work on this subject shows that there is a distinct division of opinion on the effects of dietary $\mathrm{Ca}$ salts, and the $\mathrm{Ca}: \mathrm{P}$ ratio, on $\mathrm{Fe}$ absorption.

On the one hand, Kletzien (1935, 1938, 1940) found that, in both rats and mice, many $\mathrm{Ca}$ salts reduced $\mathrm{Fe}$ storage in the liver, whereas phosphates did not. Shelling \& Josephs (1934) and Anderson, McDonough \& Elvehjem (1940) also observed that Fe utilization was most efficient when the Ca:P ratio was low. Nordfeldt (1939) reported that calcium-lactate supplements increased the negative Fe balance of mature rats on a cow's milk diet, and Fuhr \& Steenbock (1943) found that excessive dietary $\mathrm{CaCO}_{3}$ reduced blood haemoglobin and $\mathrm{Fe}$ storage.

On the other hand, the view that low dietary $\mathrm{Ca}$ or high dietary phosphate will inhibit $\mathrm{Fe}$ absorption seems to have gained wide acceptance (McLester, 1927-49; McCance \& Widdowson, 1944; Anonymous, 1950, 195 I). It seems to date from the early experiments of von Wendt (1905) and Sherman (1907), and, although their methods were criticized by Davidson \& Leitch (1933-4), there is also more recent evidence in its favour. Day \& Stein (1938) reported that anaemia developed in rats fed on a high-P diet, unless $\mathrm{Ca}$ or some other phosphate-binding ion was also fed; Orten, Smith \& Mendel (1936) also found that purified $\mathrm{CaCO}_{3}$ prevented anaemia in rats fed on a diet low in inorganic salts, and Happ (1922) reported that rats on a low-Ca, high-P diet developed anaemia. Further support for this view comes from Kinney, Hegsted \& Finch (1949) and Hegsted, Finch \& Kinney (1949) who have shown that rats fed on low-P diets absorb excessive quantities of Fe. Again, many workers (e.g. Waltner, 1927; Cox, Dodds, Wigman \& Murphy, 1931; Brock \& Diamond, 1934; Deobald \& Elvehjem, 1935) have demonstrated that excessive dietary $\mathrm{Fe}$ causes a negative $\mathrm{P}$ balance, presumably by forming an insoluble iron phosphate in the bowel and so preventing proper $P$ utilization. Brock (1937) also showed that dietary $\mathrm{Fe}$, while it increased faecal $\mathrm{P}$, did not affect faecal Ca. It is not unreasonable to argue the converse-that high dietary phosphate will similarly interfere with iron availability - and thence to presume that dietary $\mathrm{Ca}$ will increase iron availability by precipitating the $\mathrm{P}$ as $\mathrm{Ca}$ phosphate.

There is thus considerable support for both opinions. The conflicting evidence, together with the findings reported in this paper, indicate that some other important factor, qualitative or quantitative, has not yet been defined.

\section{SUMMARY}

I. Weanlings born of white Swiss mice on diets containing $2 \%$ added calcium carbonate were anaemic when compared with weanlings from diet-groups with 0 or $0.5 \%$ added calcium carbonate. The dams on the high-calcium carbonate diets were also anaemic.

2. The addition to the diet of ro p.p.m. iron as ferric citrate prevented the anaemia, but merely restoring the calcium: phosphorus ratio with sodium dihydrogen phosphate did not do so.

3. Second litters in all diet-groups were less anaemic than first litters. 


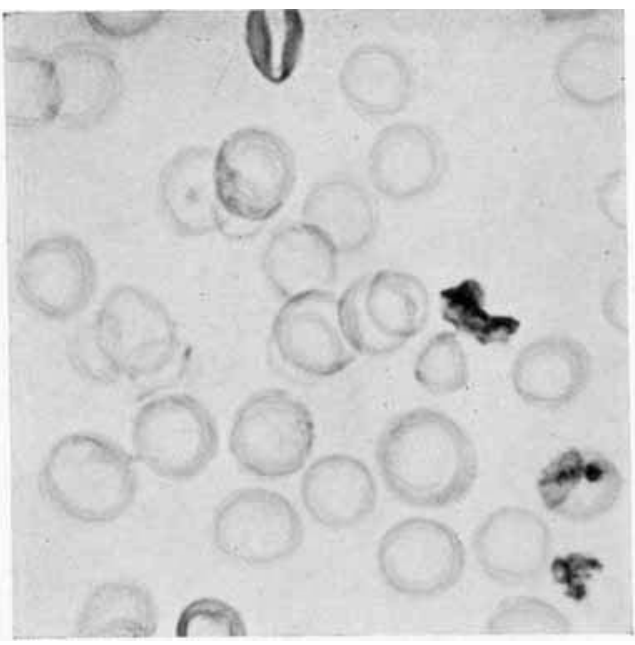

I $(a)$

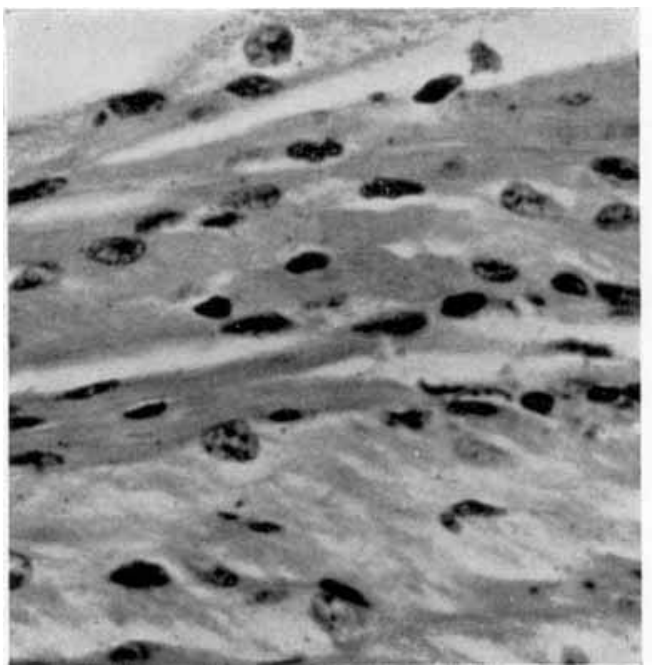

2

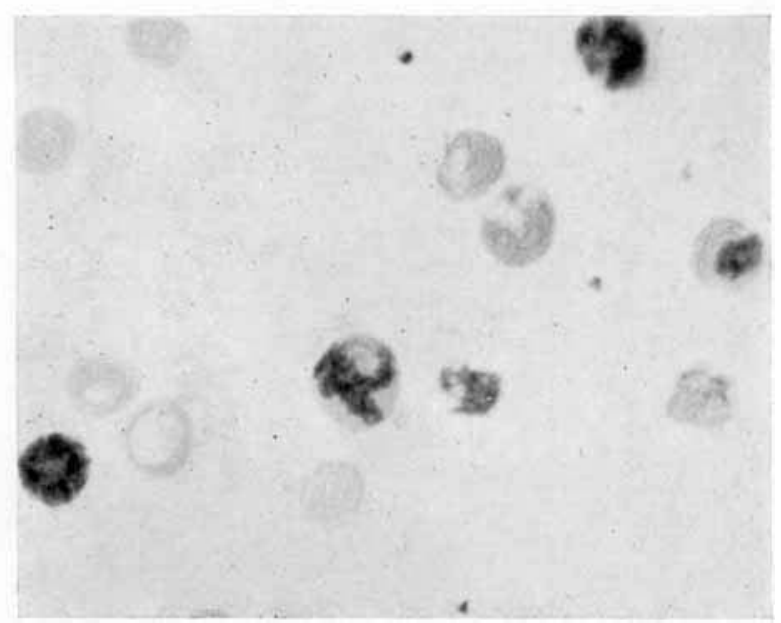

I (b)

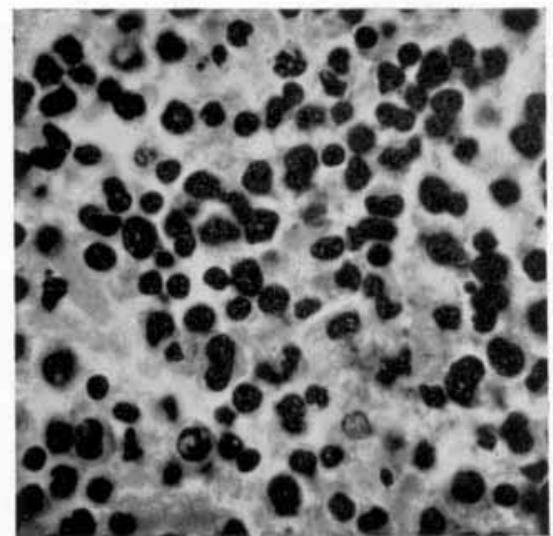

3

British Fournal of Nutrition, Vol. 6, No. 3 


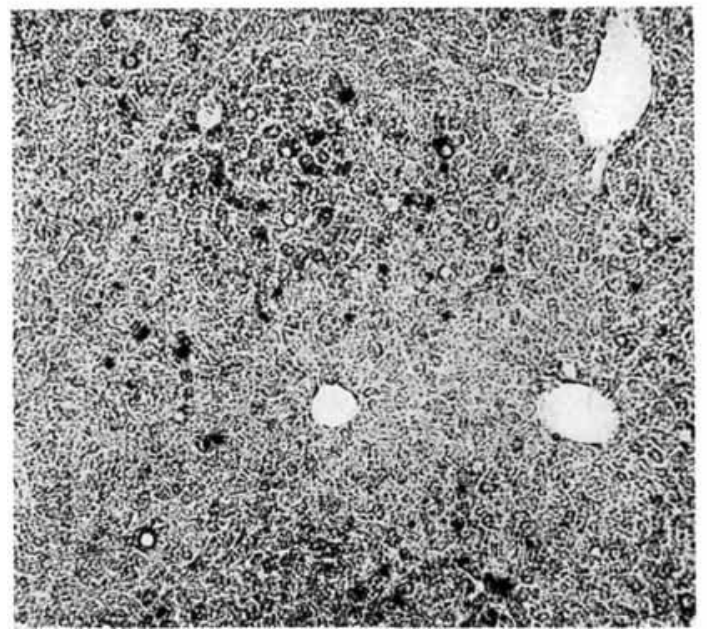

$\mathbf{I}$

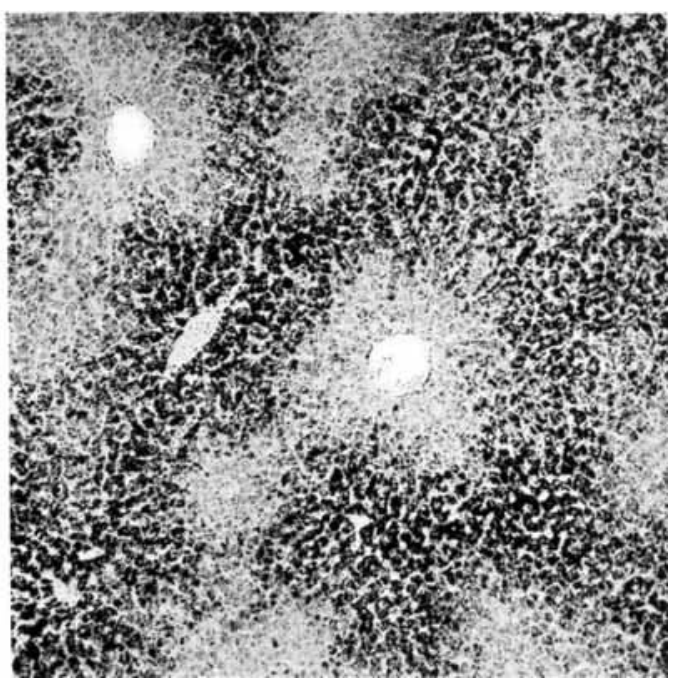

2

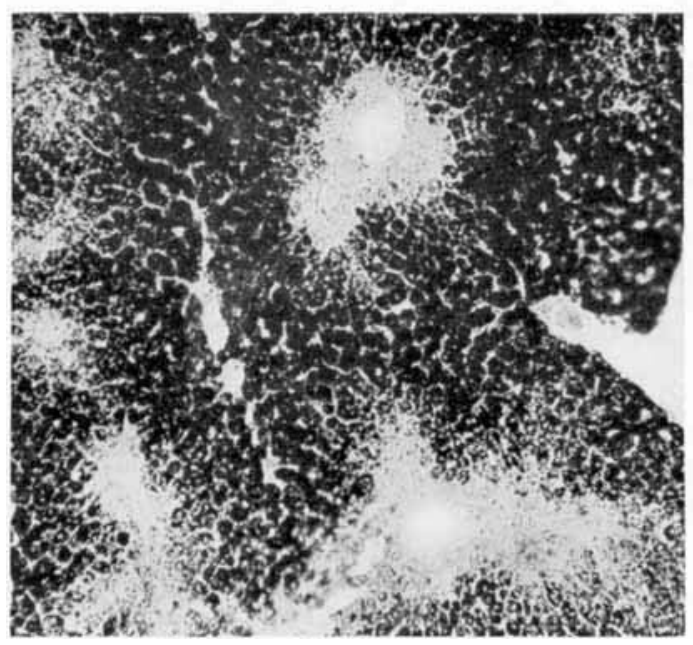

3

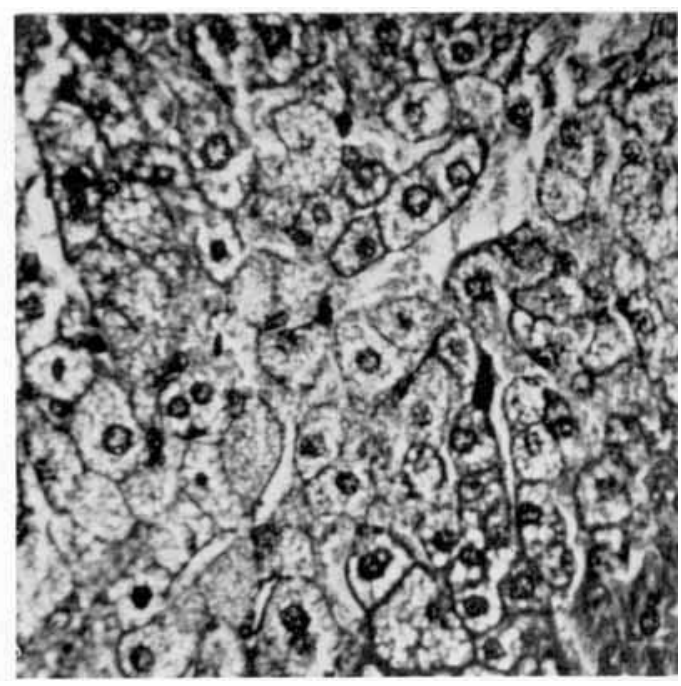

4

British Fournal of Nutrition, Vol. 6, No. 3 
4. The anaemia in both weanlings and dams presented the haematological features of iron-deficiency anaemia, except that the mean cell volume was not constantly reduced; possible reasons for this are discussed.

5. In association with the anaemia in the weanlings, there were fatty deposits in the liver, marked hyperlipaemia, and sometimes degenerative changes in other organs.

6. Consideration of the literature suggests that some unrecognized factor is important in dietary iron-calcium-phosphate relationships.

I am indebted to Messrs M. H. Quenouille and A. W. Boyne, of the Statistics Departments of the University of Aberdeen and the Rowett Research Institute, for advice on the design of Exp. 2, and for statistical analysis of the experimental data. I am also grateful to Mr Edward Rattray for technical assistance.

\section{EXPLANATION OF PLATES}

\section{Plate I}

I. Blood films from weanling mice from high calcium-carbonate diet-groups, $a$ stained Leishman, $\times 1800 ; b$ stained brilliant cresyl blue supravitally and Leishman, $x_{1500}$. Note the hypochromasia, anisocytosis and poikilocytosis, and, in $b$, the normoblasts and reticulocytes.

2. Heart muscle of weanling mouse from high calcium-carbonate diet-group. Note hypertrophy of the fibres and, in the lower half, degenerative changes. Haemalum and eosin, $\times 700$.

3. Section of bone marrow of weanling mouse from high calcium-carbonate diet-group. Note the normoblastic hyperplasia. Haemalum and eosin, $\times 65^{\circ}$.

\section{Plate 2}

I, 2 and 3. Livers of weanling mice, containing varying amounts of fat (appears dark). Frozen sections, Scharlach $R$ and haemalum. $1, \times 108 ; 2, \times 80 ; 3, \times 95$.

4. Liver of weanling mouse, to show the 'foam-cells' typical of the fatty degeneration. Haemalum and eosin, $\times 400$.

\section{REFERENCES}

Anderson, H. D., McDonough, K. B. \& Elvehjem, C. A. (1940). Y. Lab. clin. Med. $25,464$. Anonymous (1950). Nutr. Rev.8, 7 .

Anonymous (195I). Brit. med. F. i, 231 .

Bacharach, A. L., Cuthbertson, W. J. F. \& Thornton, D. M. (1949). Brit. F. Nutrit. 3, 3.

Brock, J. F. (1937). Clin. Sci. 3, 37.

Brock, J. F. \& Diamond, L. K. (r934). F. Pediat. 4, 442.

Cappell, D. F., Hutchison, H. E. \& Smith, G. H. (1947). Brit. med. F. i, 403.

Cox, G. J., Dodds, M. L., Wigman, H. B. \& Murphy, F. J. (I93I). F. biol. Chem. 92, xi.

Davidson, L. S. P. \& Leitch, I. (1933-4). Nutr. Abstr. Rev. 3, 901 .

Day, H. G. \& Stein, H. J. (1938). F. Nutrit. 16, 525.

Deobald, H. J. \& Elvehjem, C. A. (1935). Amer. F. Physiol. IrI, II8.

Fuhr, I. \& Steenbock, H. (r943). f. biol. Chem. 147, 71.

Haldane, J. (r901). F. Physiol. 26, 497.

Happ, W. M. (1 922). Fohns Hopk. Hosp. Bull. 33, 163.

Hegsted, D. M., Finch, C. A. \& Kinney, T. D. (1949). F. exp. Med. 90, 147.

Heller, V. G. \& Paul, H. (1934). F. Lab. clin. Med. 19, 777.

King, E. J. (1946). Micro-analysis in Medical Biochemistry. London: J. and A. Churchill.

Kinney, T. D., Hegsted, D. M. \& Finch, C. A. (1949). F. exp. Med. 90, 137.

Kletzien, S. W. (1935). F. Nutrit. 9, suppl., p. 9.

Kletzien, S. W. (1938). Э. Nutrit. 15, suppl., p. 16.

Kletzien, S. W. (1940). F. Nutrit. r9, 187.

Lendrum, A. C. (1943). Brit. med. F. ii, 644 .

McCance, R. A. \& Widdowson, E. M. (1944). Ann. Rev. Biochem. 13, 315.

McLester, J. S. (1927-49). Nutrition and Diet in Health and Disease, Ist -5 th eds. Philadelphia and London: W. B. Saunders. Co. 
Mayer, P. (1903-4). Z. wiss. Mikr. 20, 409.

Nordfeldt, S. (1939). Skand. Arch. Physiol. 83, 7.

Orten, J. M., Smith, A. H. \& Mendel, L. B. (1936). F. Nutrit. 12, 373.

Parsons, L. G. (1938). Lancet, 234, 65.

Price-Jones, C. (1932). F. Path. Bact. 35, 759.

Richards, M. B. \& Greig, W. A. (1952). Brit. Y. Nutrit. 6, 265.

Schmidt, M. B. (1928). Der Einfluss Eisenarmer und Eisenreicher Nahrung auf Blut und Körper. Jena: Gustav Fischer.

Shelling, D. H. \& Josephs, H. W. (1934). Johns Hopk. Hosp. Bull. 55, 309.

Sherman, H. C. (г907). Bull. U.S. Dep. Agric. no. I 85.

Sherman, H. C. \& Campbell, H. L. (1924). F. biol. Chem. 6o, 5.

von Wendt, G. (1905). Skand. Arch. Physiol. 17, 211.

Waltner, K. (1927). Biochem. Z. 188, 381 .

Whitby, L. E. H. \& Britton, C. J. C. (1950). Disorders of the Blood, 6th ed. London: J. and A. Churchill. 